\title{
Pretreatment with dexmedetomidine alleviates lung injury in a rat model of intestinal ischemia reperfusion
}

\author{
${\text { YAPING } \mathrm{CHEN}^{1 *}, \text { WENYU BIAN }}^{2 *}$ and $\mathrm{BO} \mathrm{XU}^{3}$ \\ ${ }^{1}$ Department of Anesthesiology, Jinshan Hospital, Fudan University, Shanghai 200000; ${ }^{2}$ Department of Anesthesiology, \\ Renji Hospital, Jiaotong University School of Medicine, Shanghai 200127; ${ }^{3}$ Department of Anesthesiology and SICU, \\ Xinhua Hospital, Jiaotong University School of Medicine, Shanghai 200092, P.R. China
}

Received July 4, 2019; Accepted November 18, 2019

DOI: $10.3892 / \mathrm{mmr} .2020 .10942$

\begin{abstract}
The aim of the present study was to investigate the antioxidant mechanisms of dexmedetomidine against lung injury during intestinal ischemia reperfusion (IIR) in rats. The model of IIR-induced acute lung injury was established by occluding the superior mesenteric artery (SMA) for $1 \mathrm{~h}$ and reperfusing for $2 \mathrm{~h}$ using Sprague-Dawley rats. Pathological examination was used to assess the extent of the lung injury. Oxidative stress was evaluated by measuring malondialdehyde, myeloperoxidase and superoxide dismutase in the lung and plasma. The proinflammatory cytokines tumor necrosis factor- $\alpha$ and interleukin- 6 were determined via an enzyme-linked immunosorbent assay. The mRNA and protein expression of nuclear factor-erythroid 2 related factor 2 (Nrf2) and heme oxygenase 1 (HO-1) were determined using a reverse transcription-quantitative polymerase chain reaction and western blotting. Pretreatment with dexmedetomidine significantly inhibited the oxidative stress response and proinflammatory factor release caused by IIR compared with the normal saline group (MDA and SOD in lung and plasma, $\mathrm{P}<0.05$; MPO, IL-1 $\beta$ and TNF- $\alpha$ in lung and plasma, $\mathrm{P}<0.05)$. Dexmedetomidine improved pulmonary pathological changes in IIR rats compared with the normal saline group. Investigations into the molecular mechanism revealed that dexmedetomidine increased the expression levels of Nrf2 and HO-1 via activating $\alpha 2$ adrenergic receptors compared with the normal saline group. The antagonism of $\alpha 2$ adrenergic receptors may reverse the protective effect of dexmedetomidine on lung injury during IIR, including decreasing the
\end{abstract}

Correspondence to: Dr Bo Xu, Department of Anesthesiology and SICU, Xinhua Hospital, Jiaotong University School of Medicine, 1665 Kongjiang Road, Shanghai 200092, P.R. China

E-mail: xubo@xinhuamed.com.cn

*Contributed equally

Key words: lung injury, intestinal ischemia-reperfusion, dexmedetomidine, nuclear factor-erythroid 2 related factor 2 , heme oxygenase 1 expression levels of $\mathrm{Nrf} 2$ and $\mathrm{HO}-1$, elevating the oxidative stress response and increasing the proinflammatory factor release. In conclusion, pretreatment with dexmedetomidine demonstrated protective effects against lung injury during IIR via $\alpha 2$ adrenergic receptors. The Nrf2/HO-1 signaling pathway may serve a function in the protective effect of dexmedetomidine.

\section{Introduction}

Intestinal ischemia reperfusion (IIR) injury always occurs following intestinal obstruction, shock, intestinal torsion and mesenteric artery occlusion (1-3). IIR frequently causes lung injury, including acute lung injury (ALI) and acute respiratory distress syndrome (ARDS) (4,5). Oxidative stress serves important functions in lung injury induced by IIR, as free radicals are able to attack a number of cell constituents (6) and activate the processes of inflammation through transcription factors $(7,8)$. Hence, antioxidant therapy against lung injury during IIR is imperative.

Dexmedetomidine (DEX) is primarily administered during intensive care and anesthesia due to its sedative and analgesic effects (9). It has been demonstrated that DEX is able to suppress oxidative stress in lipopolysaccharide-induced liver injury by exerting its effects on $\alpha 2$ adrenoreceptors (10), suggesting a potential protective effect for diseases associated with oxidative stress. The transcription factor nuclear factor-erythroid 2 related factor 2 (Nrf2) is able to bind to antioxidant response elements, including heme oxygenase 1 (HO-1), which antagonize reactive oxygen species (ROS)-associated oxidative stress $(11,12)$. Activation of Nrf2 has been confirmed to rescue signaling pathways in order to inhibit oxidative pulmonary injury and abnormal inflammatory response to protect against lung injury in Staphylococcus aureus pneumonia $(13,14)$. Hence, the aim of the present study was to investigate the effect of DEX on IIR-induced lung injury and determine whether the protective function depended on the $\mathrm{Nrf} 2 / \mathrm{HO}-1$ pathway.

\section{Materials and methods}

Animals. The present study was approved by the animal welfare committee of Fudan University (Shanghai, China). All experimental procedures of the present study were performed 
in compliance with the National Institutes of Health Guide for the Care and Use of Laboratory Animals (15). Adult male Sprague-Dawley (SD) rats (8-12 weeks old, 200-250 g) were provided by the Animal Experimental Center of Fudan University. The animals were housed in a room with a $12 \mathrm{~h}$ light-dark cycle under controlled environmental conditions with a temperature of $22 \pm 1^{\circ} \mathrm{C}$ and a relative humidity of $55 \pm 5 \%$. Water and food were available ad libitum. All rats were acclimatized to these conditions for 1 week prior to the study. There were 110 rats used in total in the present study.

IIR protocol and animal groups. Rats were anesthetized using pentobarbital (50 mg/kg; Sigma-Aldrich; Merck KGaA, Darmstadt, Germany) by intraperitoneal injection. Once the midline abdominal incision was performed, the superior mesenteric artery (SMA) was isolated and occluded for $60 \mathrm{~min}$ with an atraumatic microvascular clamp $(16,17)$. Then, the clip was then gently release and the bowel perfusion was controlled by the presence of a pulse. The abdominal wall was sutured prior to recovering from anesthesia. After a $2 \mathrm{~h}$ reperfusion period, blood samples $(5 \mathrm{ml}$ each sample) from each animal were collected from the arterial line. A certain quantity of heparinized blood was used for the measurement of arterial blood gas with automated blood gas analyzer (ABL80 FLEX, Radiometer). Other samples were centrifuged at 3,500 x g for $15 \mathrm{~min}$ at $4^{\circ} \mathrm{C}$ to separate the serum. Serum samples were stored at $-80^{\circ} \mathrm{C}$ for further analysis. Meanwhile, lung tissues were collected for histopathologic and biochemical analyses. Then, the rats were decapitated under deep anesthesia. If the rats went into shock or the IIR model was aborted, the animals were euthanized. The duration of the experiment lasted $\sim 4 \mathrm{~h}$.

In the present study two experiments were performed. Experiment 1 was designed to test the effects of DEX (Jiangsu Hengrui Medicine Co., Ltd., Jiangsu, China) pretreatment on pathological damage to the lung during IIR and to select the optimal drug dose. At present, the majority of researchers have selected 25-50 $\mu \mathrm{g} / \mathrm{kg}$ DEX (injected intraperitoneally) in order to study its protection against ischemia reperfusion injury (18-20). Intravenous injection of DEX always requires small doses ranging from 1 to $10 \mu \mathrm{g} / \mathrm{kg}(21,22)$. Hence, in the present study, three different doses were assessed to select the optimal dose intraperitoneally. A total of $60 \mathrm{SD}$ male rats were randomly divided into 6 groups ( $n=10$ per group), as follows: Control group, IIR group, IIR + normal saline (NS) group, IIR + DEX $(10 \mu \mathrm{g} / \mathrm{kg})$ group, IIR + DEX (30 $\mu \mathrm{g} / \mathrm{kg})$ group and IIR + DEX $(90 \mu \mathrm{g} / \mathrm{kg})$ group. Rats in the control group only underwent laparotomy without an intraperitoneal operation. In the IIR + DEX groups, DEX was intraperitoneally injected into the rats prior to releasing the clamp. If DEX was able to protect against lung injury during IIR, the best dose of DEX was selected based on if it altered the pathological lesions substantially without obvious side effects. The same volume of normal saline was selected to be the control.

Experiment 2 was designed to study the effects of DEX pretreatment on the $\mathrm{Nrf} / \mathrm{HO}-1$ signaling pathway and whether its action depended on an $\alpha 2$-adrenergic receptor. Oxidative damage and inflammatory response were also detected. A total of $50 \mathrm{SD}$ male rats were randomly divided into 5 groups ( $n=10$ per group), as follows: Control group, IIR group, IIR + $\mathrm{NS}$ group, IIR + DEX group and IIR + DEX + atipamezole
(ATI; $\alpha 2$-adrenergic antagonist; Sigma-Aldrich; Merck $\mathrm{KGaA}$ ) group. Once the optimal dose of DEX was determined, the corresponding dose of $\alpha 2$-adrenergic receptor antagonist ATI was selected.

Reverse transcription-quantitative polymerase chain reaction $(R T-q P C R)$. Total RNA of the lung tissues was isolated using TRIZOL $^{\circledR}$ reagent (Invitrogen; Thermo Fisher Scientific, Inc., Waltham, MA, USA) according to the manufacturer's protocol. cDNA was synthesized using the RevertAid First Strand cDNA Synthesis kit (Thermo Fisher Scientific, Inc.) with the following reaction conditions: $25^{\circ} \mathrm{C}$ for $10 \mathrm{~min}, 42^{\circ} \mathrm{C}$ for $1 \mathrm{~h}$, $72^{\circ} \mathrm{C}$ for $10 \mathrm{~min}$ and a $4^{\circ} \mathrm{C}$ hold. PCR was performed according to the following thermocycling conditions: Predenaturation for $2 \mathrm{~min}$ at $95^{\circ} \mathrm{C}$ for a cycle, denaturation for $15 \mathrm{sec}$ at $95^{\circ} \mathrm{C}$, annealing for $15 \mathrm{sec}$ at $60^{\circ} \mathrm{C}$ and extension for $1 \mathrm{~min}$ at $72^{\circ} \mathrm{C}$ with 40 cycles from denaturation to extension. RT-qPCR was performed using the SYBR green method (FastStart Universal SYBR Master; Roche Diagnostics, Basel, Switzerland) and a MiniOpticon RT-qPCR detection system (Bio-Rad Laboratories, Inc., Hercules, CA, USA). The method $2^{-\Delta \Delta C q}$ was used to determine the relative quantification of the target gene expression (23). $\beta$-actin was selected as the house-keeping gene. The following PCR primers (Sangon Biotech Co., Ltd. Shanghai, China) were used: Nrf2 forward, 5'-CACAGTGCT CCTATGCGTGA-3' and reverse, 5'-TTCTGGGCGGCGACT TTATT-3'; HO-1 forward, TGATGGCCTCCTTGTACC-3' and reverse, 5'-GTGGGGCATAGACTGGGTTC-3'; $\beta$-actin forward, 5'-GGAAATCGTGCGTGACATTAAAG-3' and reverse, 5'-CGGCAGTGGCCATCTCTT-3'.

Western blotting. T-PER protein extraction reagents (Thermo Fisher Scientific Inc.) were used to extract the proteins of lung tissues. Subsequently, the protein concentration in each sample was determined using a BCA protein assay (Bio-Rad Laboratories, Inc.). Equal amounts of proteins (30 $\mu \mathrm{g}$ per sample) were separated using 10\% SDS-PAGE gel, transferred to polyvinylidene difluoride membrane (Bio-Rad Laboratories, Inc.). blocked with 5\% nonfat dry milk at room temperature for $1 \mathrm{~h}$ and incubated with primary antibodies against HO-1 (1:200; cat. no. sc-136960; Santa Cruz Biotechnology, Inc.), Nrf2 (1:200; cat. no. sc-365949; Santa Cruz Biotechnology, Inc.) and GAPDH (1:1,000; cat. no. sc-365062; Santa Cruz Biotechnology, Inc.) overnight at $4^{\circ} \mathrm{C}$. Then, the membranes were washed and incubated with anti-rabbit immunoglobulin G (IgG)-HRP (sc-2357) or anti-mouse IgG-HRP (sc-2005) secondary antibodies (1:2,000; Santa Cruz Biotechnology, Inc.) for $2 \mathrm{~h}$ at $37^{\circ} \mathrm{C}$. Proteins were visualized using enhanced chemiluminescent reagents (Beyotime Institute of Biotechnology, Jiangsu, China). The expression of GAPDH was used as an internal control. The optical density of the bands was measured using a densitometer (Syngene Europe) together with Genesnap 4.0 and Genetools 4.0 software (Syngene Europe).

Biochemical analysis of lung tissues and plasma. The lung tissues and plasma were used to evaluate the malondialdehyde (MDA) levels and the myeloperoxidase (MPO) and the superoxide dismutase (SOD) activities using a MDA detection kit (A003-1-2), a MPO detection kit (A044-1-1) and a SOD 


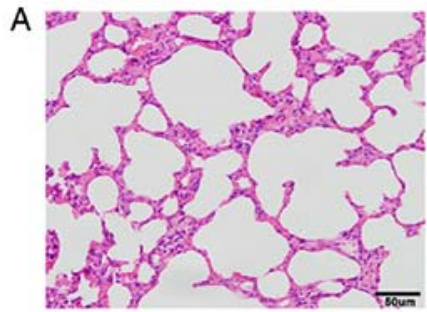

Control

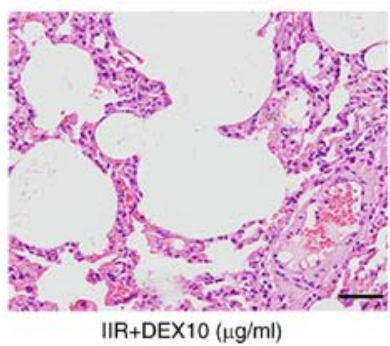

IIR+DEX10 $(\mu \mathrm{g} / \mathrm{ml})$

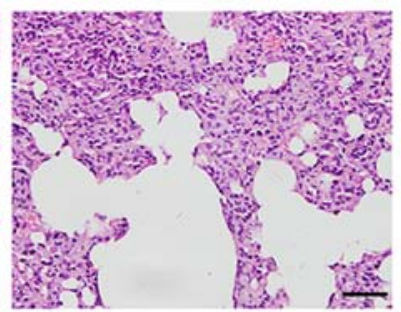

IIR

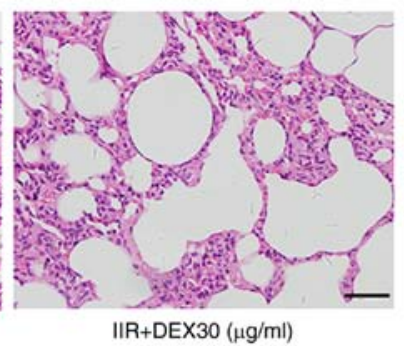

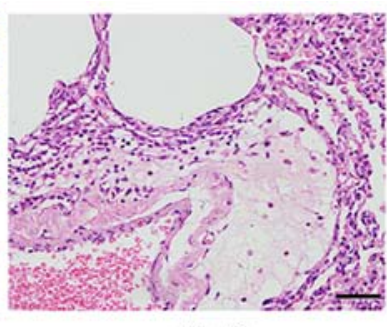

IIR $+\mathrm{NS}$

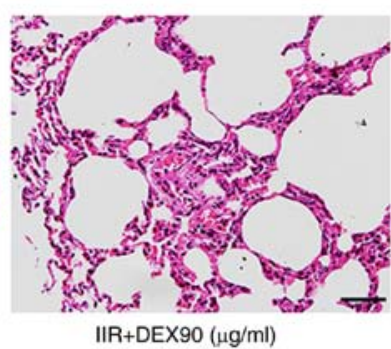

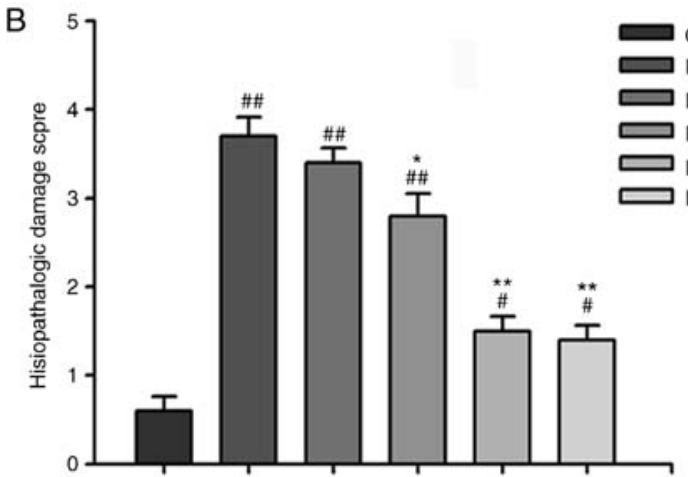

Figure 1. Histopathological changes in the lung tissue of control, IIR, IIR + NS, IIR + DEX (10 $\mu \mathrm{g} / \mathrm{kg}), \mathrm{IIR}+\mathrm{DEX}(30 \mu \mathrm{g} / \mathrm{kg}) \mathrm{and}$ IIR $+\mathrm{DEX}(90 \mu \mathrm{g} / \mathrm{kg})$ groups. (A) Tissue sections of the lung tissue stained with hematoxylin and eosin in different groups. Magnification, $\mathrm{x} 40$. (B) Pathological damage scores of the lung tissue in the control, IIR + NS, IIR + DEX $(10 \mu \mathrm{g} / \mathrm{kg})$, IIR + DEX $(30 \mu \mathrm{g} / \mathrm{kg})$ and IIR + DEX $(90 \mu \mathrm{g} / \mathrm{kg}) \mathrm{groups}$. Data are presented as the mean \pm standard error of the mean. ${ }^{\#} \mathrm{P}<0.05$ vs. control group; ${ }^{\# *} \mathrm{P}<0.01$ vs. control group; ${ }^{*} \mathrm{P}<0.05$ vs. IIR $+\mathrm{NS}$ group; ${ }^{* *} \mathrm{P}<0.01$ vs. IIR $+\mathrm{NS}$ group. IIR, intestinal ischemia reperfusion; DEX, dexmedetomidine; NS, normal saline.

detection kit (A001-3-2) (Nanjing Jiancheng Bioengineering Institute, Nanjing, China), respectively, according to the manufacturer's protocol.

Enzyme-linked immunosorbent assay (ELISA). Whole blood was centrifuged for $15 \mathrm{~min}$ at $1,000 \mathrm{x} \mathrm{g}$ at $4^{\circ} \mathrm{C}$ subsequent to collection. Plasma was removed immediately for further analysis. Lung tissues were rinsed with ice-cold phosphate buffered saline (PBS; 0.01 M, pH=7.4) to remove excess blood thoroughly. Tissue pieces were weighed and then minced into small pieces which were homogenized in PBS with a glass homogenizer on ice. The homogenates were then centrifuged for $15 \mathrm{~min}$ at $4,000 \mathrm{x} \mathrm{g}$ at $-20^{\circ} \mathrm{C}$ to obtain the supernatant. The plasma and supernatant were collected for ELISA. Interleukin-1 $\beta$ (IL-1 $\beta$, F15810) and tumor necrosis factor- $\alpha$ (TNF- $\alpha$, F16960) concentrations in the plasma and supernatant were measured using the ELISA kits (Shanghai Westang Bio-Tech Co., Ltd.) in accordance with the manufacturer's protocols.

Histopathology assessment. Lung tissues were harvested $2 \mathrm{~h}$ following IIR and were fixed in $4 \%$ paraformaldehyde in PBS at room temperature for $2 \mathrm{~h}$. Sections were stained with $0.45 \%$ hematoxylin for $10 \mathrm{~min}$ and $0.5 \%$ eosin for $2 \mathrm{~min}$ at room temperature and observed under light microscopy (magnification, $x 40)$ to detect lung injury. Severity of lung injury was evaluated as described from 0 to 5 grades (24): 0 , normal tissue; 1 , minimal inflammatory change; 2 , mild to moderate inflammatory changes (no obvious damage to the lung architecture); 3, moderate inflammatory injury (thickening of the alveolar septae); 4, moderate to severe inflammatory injury (formation of nodules or areas of pneumonitis that distorted the normal architecture); and 5, severe inflammatory injury with total obliteration of the field.

Statistical analysis. All data were analyzed using SPSS 20.0 software (IBM Corp., Armonk, NY, USA). Difference was assessed using a one-way analysis of variance. Dunnett's test was used for multiple comparisons. Data are expressed as the mean \pm standard error of the mean. $\mathrm{P}<0.05$ was considered to indicate a statistically significant difference.

\section{Results}

DEX alleviates IIR-induced lung injury. Lung tissue in the IIR group was markedly damaged with aberrant alveolar structures, 
Table I. Arterial blood gas levels $(\mathrm{n}=10)$.

\begin{tabular}{lcccccc}
\hline Item & Control group & IIR group & IIR+NS group & $\begin{array}{c}\text { IIR+DEX } \\
(10 \mu \mathrm{g} / \mathrm{kg}) \text { group }\end{array}$ & $\begin{array}{c}\text { IIR+DEX } \\
(30 \mu \mathrm{g} / \mathrm{kg}) \text { group }\end{array}$ & $\begin{array}{c}\text { IIR+DEX } \\
(90 \mu \mathrm{g} / \mathrm{kg}) \text { group }\end{array}$ \\
\hline $\mathrm{pH}$ & $7.36+0.019$ & $7.22+0.012^{\mathrm{a}}$ & $7.21+0.033^{\mathrm{a}}$ & $7.24+0.009^{\mathrm{a}}$ & $7.31+0.022^{\mathrm{b}, \mathrm{c}}$ & $7.29+0.013^{\mathrm{a}}$ \\
$\mathrm{PaO}_{2}$ & $97.34+2.76$ & $74.33+1.63^{\mathrm{a}}$ & $74.05+1.24^{\mathrm{a}}$ & $76.42+1.72^{\mathrm{a}}$ & $88.46+1.56^{\mathrm{a}, \mathrm{c}, \mathrm{e}}$ & $82.74+1.20^{\mathrm{a}, \mathrm{c}, \mathrm{e}}$ \\
$\mathrm{PaCO}_{2}$ & $37.04+0.84$ & $45.15+1.00^{\mathrm{a}}$ & $44.22+1.78^{\mathrm{a}}$ & $42.91+0.88^{\mathrm{a}}$ & $39.79+1.00^{\mathrm{d}}$ & $40.01+1.04^{\mathrm{d}}$ \\
\hline
\end{tabular}

${ }^{a} \mathrm{P}<0.01$ and ${ }^{\mathrm{b}} \mathrm{P}<0.05$ vs. control group, ${ }^{\mathrm{C}} \mathrm{P}<0.01$ and ${ }^{\mathrm{d}} \mathrm{P}<0.05$ vs. IIR + NS group. ${ }^{\mathrm{e}} \mathrm{P}<0.05$ vs. IIR $+\mathrm{DEX}(30 \mu \mathrm{g} / \mathrm{kg})$ group. IIR, intestine ischemia reperfusion; DEX, dexmedetomidine; NS, normal saline.

Table II. Expression levels of SOD and MDA in the lung and plasma of different groups $(\mathrm{n}=10)$.

\begin{tabular}{lcrrr}
\hline Item & Control group & IIR group & IIR + NS group & IIR + DEX group \\
\hline Pulmonary SOD (U/ml) & $37.19 \pm 1.14$ & $31.21 \pm 1.16^{\mathrm{b}}$ & $32.08 \pm 0.58^{\mathrm{b}}$ & $33.41 \pm 0.93^{\mathrm{d}}$ \\
Pulmonary MDA (nmol/ml) & $2.61 \pm 0.08$ & $3.16 \pm 0.06^{\mathrm{b}}$ & $3.15 \pm 0.08^{\mathrm{b}}$ & $2.90 \pm 0.06^{\mathrm{d}}$ \\
Plasma SOD (U/ml) & $43.77 \pm 0.91$ & $33.27 \pm 1.45^{\mathrm{b}}$ & $33.00 \pm 1.36^{\mathrm{b}}$ & $40.30 \pm 0.69^{\mathrm{a}, \mathrm{d}}$ \\
Plasma MDA (nmol/ml) & $2.92 \pm 0.12$ & $3.45 \pm 0.04^{\mathrm{b}}$ & $3.40 \pm 0.06^{\mathrm{b}}$ & $3.13 \pm 0.06^{\mathrm{c}}$ \\
\hline
\end{tabular}

${ }^{\mathrm{a}} \mathrm{P}<0.05$, ${ }^{\mathrm{b}}<0.01$ vs. control group, ${ }^{\mathrm{c}} \mathrm{P}<0.05,{ }^{\mathrm{d}} \mathrm{P}<0.01 \mathrm{vs}$. IIR + NS group. SOD, superoxide dismutase; MDA, malondialdehyde; IIR, intestine ischemia reperfusion; DEX, dexmedetomidine; NS, normal saline.

notable cell infiltration, alveolar thickening and diffuse interstitial edema (Fig. 1A). The alveolar structures were integral in the control group. An intraperitoneal injection of DEX at a concentration of $10 \mu \mathrm{g} / \mathrm{kg}$ did not decrease the pulmonary damage induced by IIR (Fig. 1A). However, 30 and $90 \mu \mathrm{g} / \mathrm{kg}$ DEX substantially alleviated IIR-associated lung injury to a similar degree (Fig. 1A). The histopathological injury scores in all groups are presented in Fig. 1B. Arterial blood gas levels were also detected following reperfusion for $2 \mathrm{~h} . \mathrm{PaO}_{2}$ and $\mathrm{pH}$ were significantly lower in the IIR group compared with the control group (Table I). Although 30 and $90 \mu \mathrm{g} / \mathrm{kg}$ DEX significantly increased oxygenation compared with the IIR + NS group $(\mathrm{P}<0.01)$, rats with $90 \mu \mathrm{g} / \mathrm{kg} \mathrm{DEX}$ exhibited more adverse drug reactions, including a longer sedation time and greater urinary volume. Hence, $30 \mu \mathrm{g} / \mathrm{kg}$ DEX was selected for further experiments in order to determine the mechanism of its protective effect on lung injury induced by IIR.

DEX decreases oxidative stress in lung tissue and plasma. In order to evaluate oxidative damage, the present study detected the MDA levels and SOD activity $(25,26)$. There was a significant increase in MDA levels in the lung tissue and plasma of the IIR group compared with the control group $(\mathrm{P}<0.05$ in the plasma; $\mathrm{P}<0.01$ in the lung; Table II). Pretreatment with DEX significantly decreased the increase in MDA level induced by IIR in the lung tissue and plasma $(\mathrm{P}<0.05$; Table II). In the IIR group, SOD activity was significantly lower compared with that in the control group $(\mathrm{P}<0.01)$. DEX pretreatment significantly improved SOD activity compared with normal saline $(\mathrm{P}<0.01$; Table II).

DEX decreases the inflammatory response. Activation and infiltration of polymorphonuclear (PMN) cells are key factors resulting in IIR (27). As a marker enzyme of PMN, MPO is able to reflect the degree of tissue PMN infiltration (28). There was a significant increase in MPO concentration in the lung tissue and plasma of the IIR group compared with the control group $(\mathrm{P}<0.01$; Table III). Pretreatment with DEX significantly suppressed the increase in MPO concentration induced by IIR in the lung tissue and plasma $(\mathrm{P}<0.01$; Table III). The expression of IL- $1 \beta$ and TNF- $\alpha$ in lung tissue and plasma was determined via ELISA. IIR caused the significantly increased release of inflammatory factors in the lung tissue and plasma compared with the control group $(\mathrm{P}<0.01$; Table IV). DEX significantly inhibited the IL-1 $\beta$ and TNF- $\alpha$ expression levels induced by IIR ( $\mathrm{P}<0.05$ in the lung; $\mathrm{P}<0.01$ in the plasma; Table IV).

DEX enhances the expression of the Nrf2/HO-1 signaling pathway in the IIR model. In order to assess whether the Nrf2/HO-1 signaling pathway serves a function in the protective effect of DEX, the present study measured the gene and protein levels of Nrf2 and HO-1. RT-qPCR revealed that the gene levels of $\mathrm{Nrf} 2$ and HO-1 were significantly downregulated in the lung tissue of IIR rats compared with the control groups ( $\mathrm{P}<0.01$; Fig. 2). DEX at $30 \mu \mathrm{g} / \mathrm{kg}$ significantly prevented the decrease in Nrf2 and HO-1 induced by IIR ( $\mathrm{P}<0.01$; Fig. 2). Protein levels of Nrf2 and HO-1 were measured via western blotting in order to investigate the effect of DEX on the IIR-induced inactivation of Nrf2/HO-1 signaling (Fig. 3A-D). Nrf2 and HO-1 protein levels in the IIR group were significantly lower compared with those in the control group $(\mathrm{P}<0.01)$. Pretreatment with DEX significantly alleviated the IIR-induced inactivation of Nrf2 and HO-1 in the lungs $(\mathrm{P}<0.01$; Fig. 3$)$. These results indicated that the Nrf2/HO-1 signaling pathway served an important role in oxidative stress. Hence, the results revealed that 
Table III. Expression levels of MPO in the lung and plasma of different groups $(\mathrm{n}=10)$.

\begin{tabular}{lcccc}
\hline Item & Control group & IIR group & IIR + NS group & IIR + DEX group \\
\hline Pulmonary MPO (U/l) & $113.28 \pm 2.79$ & $131.42 \pm 3.14^{\mathrm{b}}$ & $132.02 \pm 1.05^{\mathrm{b}}$ & $118.75 \pm 2.13^{\mathrm{c}}$ \\
Plasma MPO (U/l) & $124.10 \pm 3.06$ & $150.98 \pm 3.44^{\mathrm{b}}$ & $153.11 \pm 2.52^{\mathrm{b}}$ & $135.09 \pm 2.48^{\mathrm{a}, \mathrm{c}}$ \\
\hline
\end{tabular}

${ }^{\mathrm{a}} \mathrm{P}<0.05,{ }^{\mathrm{b}} \mathrm{P}<0.01$ vs. control group, ${ }^{\mathrm{c}} \mathrm{P}<0.01$ vs. IIR + NS group. MPO, myeloperoxidase; IIR, intestine ischemia reperfusion; DEX, dexmedetomidine; NS, normal saline.

Table IV. Expression levels of IL-1 $\beta$ and TNF- $\alpha$ in the lung and plasma of different groups $(n=10)$.

\begin{tabular}{|c|c|c|c|c|}
\hline Item & Control group & IIR group & IIR + NS group & IIR + DEX group \\
\hline Pulmonary IL-1 $\beta$ (pg/ml) & $7.10 \pm 0.21$ & $8.56 \pm 0.24^{b}$ & $7.78 \pm 0.20^{b}$ & $7.78 \pm 0.32^{\mathrm{a}, \mathrm{c}}$ \\
\hline Pulmonary TNF- $\alpha(\mathrm{pg} / \mathrm{ml})$ & $62.26 \pm 2.15$ & $72.95 \pm 1.99^{\mathrm{b}}$ & $72.77 \pm 0.69^{b}$ & $66.52 \pm 1.91^{\mathrm{c}}$ \\
\hline Plasma IL-1 $\beta(\mathrm{pg} / \mathrm{ml})$ & $7.28 \pm 0.20$ & $9.19 \pm 0.21^{\mathrm{b}}$ & $9.33 \pm 0.28^{b}$ & $8.13 \pm 0.25^{\mathrm{a}, \mathrm{d}}$ \\
\hline Plasma TNF- $\alpha$ (pg/ml) & $64.64 \pm 2.27$ & $86.37 \pm 1.90^{\mathrm{b}}$ & $85.56 \pm 1.82^{\mathrm{b}}$ & $71.28 \pm 1.39^{\mathrm{a}, \mathrm{d}}$ \\
\hline
\end{tabular}

${ }^{\mathrm{a}} \mathrm{P}<0.05,{ }^{\mathrm{b}} \mathrm{P}<0.01 \mathrm{vs}$. control group, ${ }^{\mathrm{c}} \mathrm{P}<0.05,{ }^{\mathrm{d}} \mathrm{P}<0.01 \mathrm{vs}$. IIR $+\mathrm{DEX}$ group, ${ }^{\mathrm{c}} \mathrm{P}<0.01 \mathrm{vs}$. IIR $+\mathrm{NS}$ group. IIR, intestine ischemia reperfusion; DEX, dexmedetomidine; NS, normal saline; IL- $1 \beta$, interleukin- $1 \beta$; TNF- $\alpha$, tumor necrosis factor- $\alpha$.
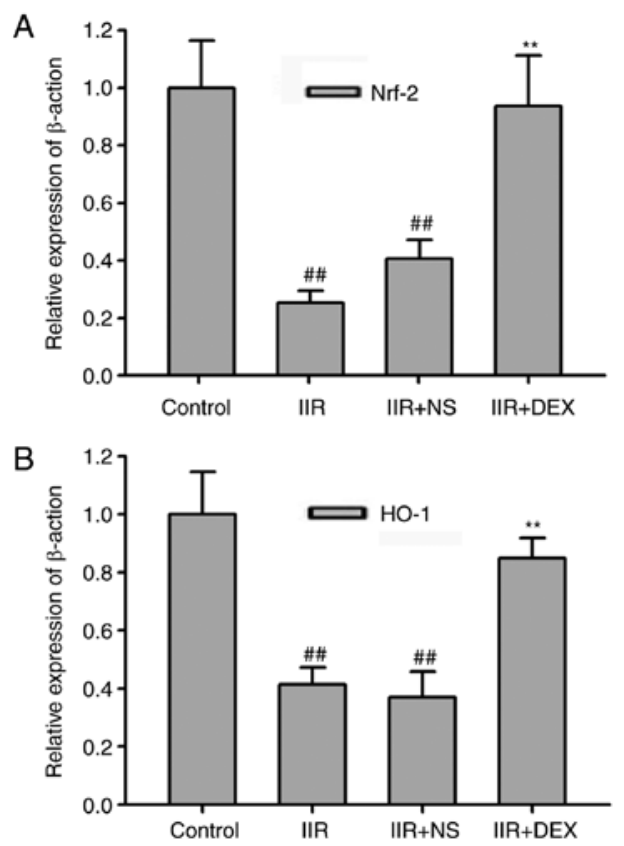

Figure 2. Reverse transcription-quantitative polymerase chain reaction analysis of Nrf2/HO-1 expression. (A) mRNA expression levels of Nrf2. (B) mRNA expression levels of HO-1. Nrf2/HO-1 mRNA expression was revealed to be significantly lower in the IIR group compared with the control group. Pretreatment with DEX increased the mRNA expression of Nrf2/HO-1 in the IIR + DEX $(30 \mu \mathrm{g} / \mathrm{kg})$ group. Data are presented as the mean \pm standard error of the mean. ${ }^{\# \prime} \mathrm{P}<0.01$ vs. control group; ${ }^{* *} \mathrm{P}<0.01$ vs. IIR + NS group. IIR, intestinal ischemia reperfusion; DEX, dexmedetomidine; NS, normal saline; Nrf2, nuclear factor-erythroid 2 related factor 2; HO-1, heme oxygenase 1.

the antioxidant effect of DEX may be associated with the Nrf2/HO-1 signaling pathway.

DEX protects against lung injury in IIR rats via an $\alpha 2$-adrenoceptor. ATI is an $\alpha 2$-adrenoceptor antagonist.
Co-treatment with ATI $(300 \mu \mathrm{g} / \mathrm{kg})$ reversed the protective effect of $30 \mu \mathrm{g} / \mathrm{kg}$ DEX on lung injury in IIR rats. The histopathological injury score in the IIR + DEX + ATI group was higher compared with that in IIR + DEX group $(\mathrm{P}<0.01$; Fig. 4A and B). A total of $300 \mu \mathrm{g} / \mathrm{kg}$ ATI also significantly inhibited the effect of DEX on the expression levels of the Nrf2/HO-1 signaling pathway ( $\mathrm{P}<0.01$; Fig. $4 \mathrm{C}$ and $\mathrm{D})$ and MDA levels and SOD activity in the lung tissue $(\mathrm{P}<0.05$; Fig. 4E and F). DEX significantly decreased the MPO concentration, IL-1 $\beta$ and TNF- $\alpha$ expression levels in the lung tissue of IIR rats compared with the NS group $(\mathrm{P}<0.01)$, which was also significantly alleviated by ATI $(\mathrm{P}<0.05$; Fig. 4G-I).

\section{Discussion}

The present study demonstrated that pretreatment with DEX had a protective effect on IIR-associated acute lung injury via the $\alpha 2$ adrenoreceptor. DEX may be activating the Nrf2/HO-1 signaling pathway in order to decrease the oxidative stress and inflammatory reaction, thus alleviating the lung injury induced by IIR.

DEX was approved by the US Food and Drug Administration in 1999 and has been used for analgesia and sedation in intensive care units (29). In animal studies, it has been demonstrated to inhibit oxidative stress and inflammatory responses to protect the kidneys, brain, intestine and heart from ischemia-reperfusion injury (16,30-34). However, to the best of our knowledge, few studies have focused on DEX on IIR-induced lung injury. The present study revealed that DEX decreased the release of TNF- $\alpha$ and IL-6. In other models of ischemia reperfusion, DEX was revealed to attenuate the apoptosis of lung alveolar epithelial cells induced by oxidative stress by inhibiting ROS generation (35). Pretreatment with DEX decreased the MDA concentration and enhanced SOD activity in patients with lung cancer during one-lung ventilation (36). The present study investigated the 

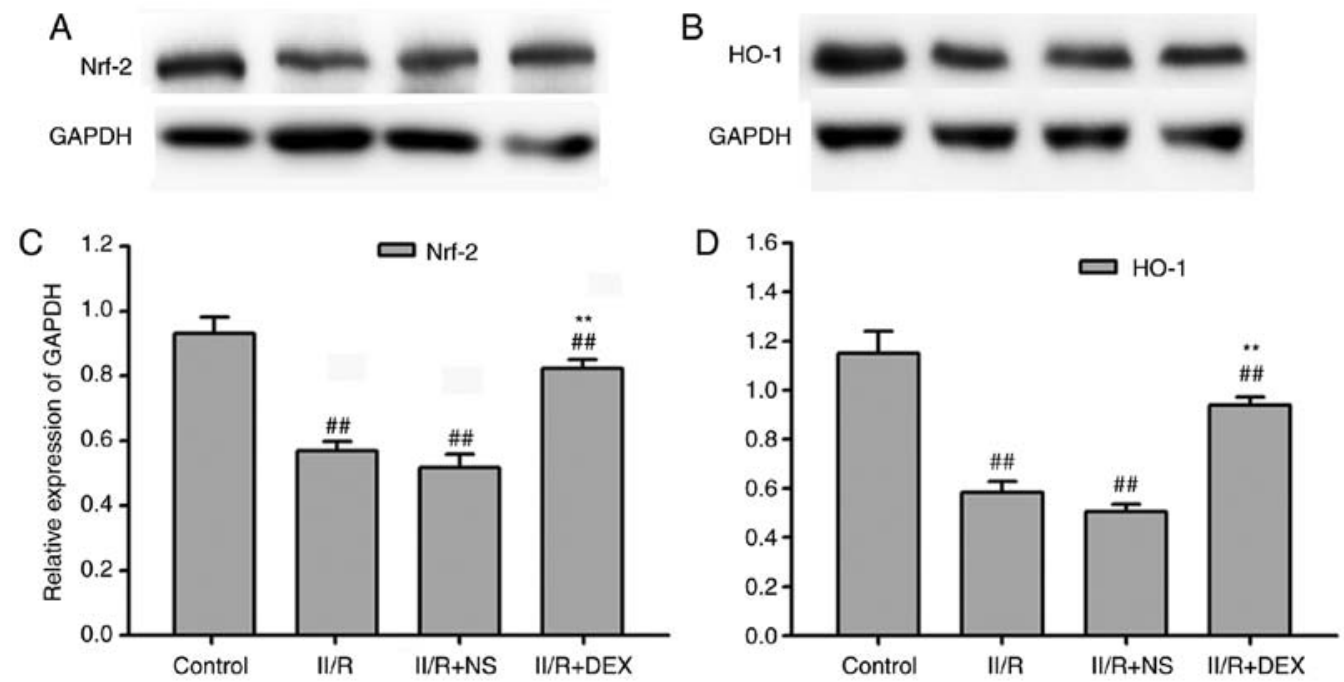

Figure 3. Western blotting of Nrf2/HO-1 expression levels. (A) Protein expression of Nrf2. (B) Protein expression of HO-1. (C) Quantified Nrf2 protein expression. (D) Quantified HO-1 protein expression. Data are presented as the mean \pm standard error of the mean. ${ }^{\# *} \mathrm{P}<0.01$ vs. control group; ${ }^{* *} \mathrm{P}<0.01$ vs. IIR + NS group. IIR, intestinal ischemia reperfusion; DEX, dexmedetomidine; NS, normal saline; Nrf2, nuclear factor-erythroid 2 related factor 2; HO-1, heme oxygenase 1 .

A

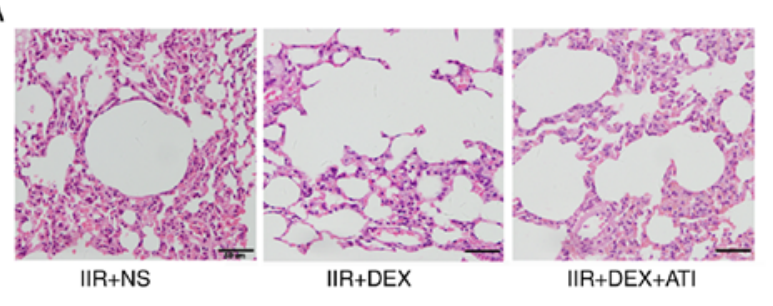

B 言 5

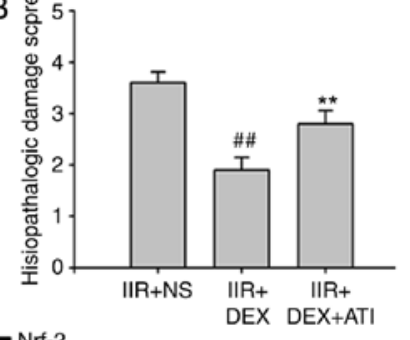

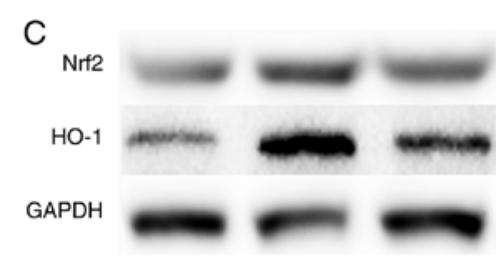

D
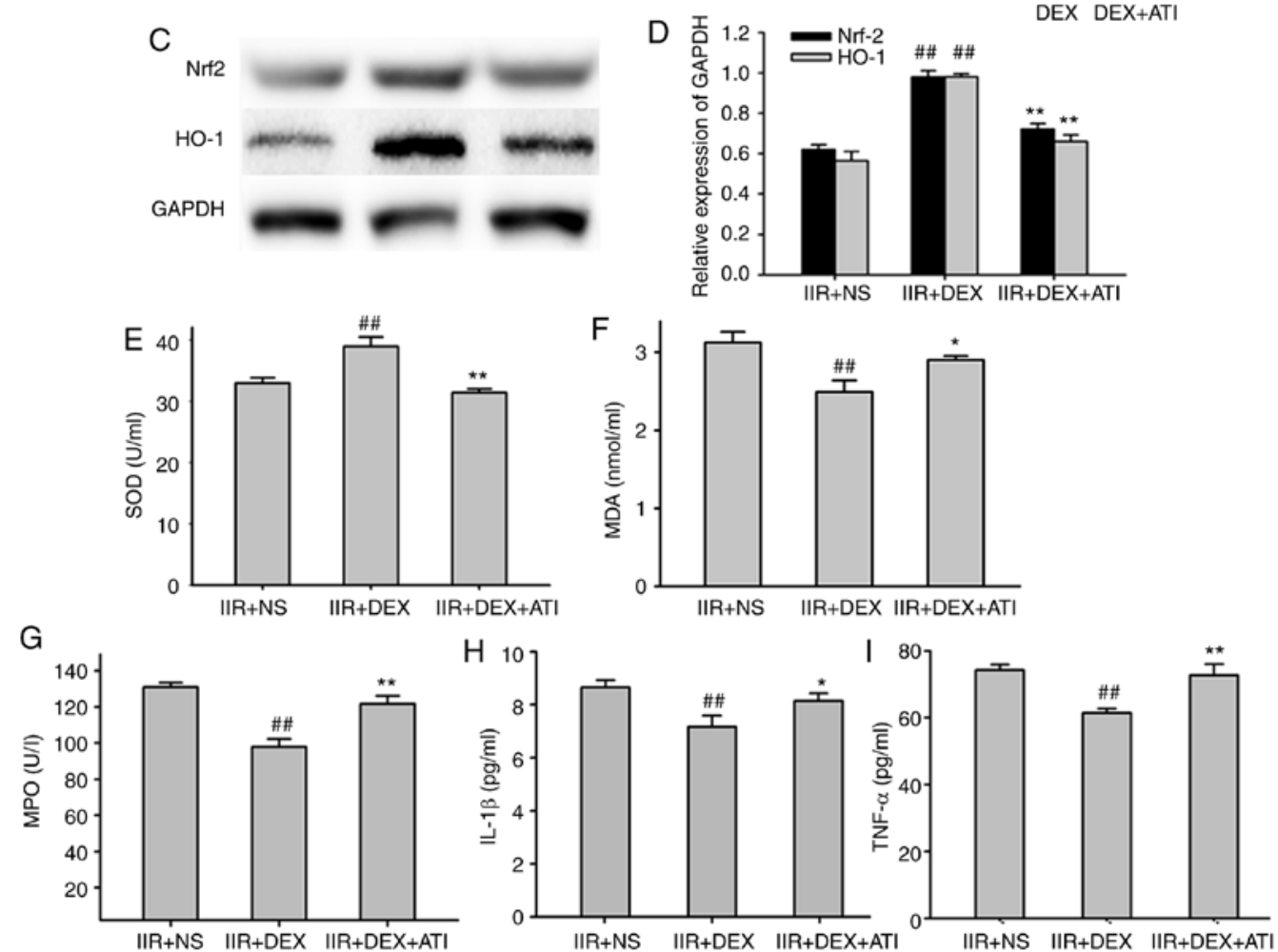

Figure 4. Protective effects of DEX on lung injury depend on $\alpha 2$-adrenergic receptors. (A) Tissue sections and (B) pathological damage scores of the lung tissue stained with hematoxylin and eosin in IIR + NS, IIR + DEX and IIR + DEX + ATI groups. Magnification, x40. (C) Western blotting of Nrf2/HO-1 expression in different groups. (D) Quantified western blotting results. Expression levels of (E) SOD and (F) MDA in the lung of different groups. Expression levels of (G) MPO, (H) IL-1 $\beta$ and (I) TNF- $\alpha$ in the lungs of different groups. ${ }^{\# \#} \mathrm{P}<0.01$ vs. IIR + NS group; ${ }^{*} \mathrm{P}<0.05$ vs. IIR $+\mathrm{DEX}$ group; ${ }^{* *} \mathrm{P}<0.01$ vs. IIR + DEX group. IIR, intestinal ischemia reperfusion; DEX, dexmedetomidine; NS, normal saline; ATI; Nrf2, nuclear factor-erythroid 2 related factor 2; HO-1, heme oxygenase 1 ; MPO, myeloperoxidase; SOD, superoxide dismutase; MDA, malondialdehyde; IL-1 $\beta$, interleukin-1 $\beta$; TNF- $\alpha$, tumor necrosis factor- $\alpha$. 
effect of DEX on lung injury during IIR, and further identified that intraperitoneal DEX significantly suppressed IIR-induced oxidation products, including MDA $(\mathrm{P}<0.01$ in the lung and $\mathrm{P}<0.05$ in the plasma), and enhanced SOD activity $(\mathrm{P}<0.01$ in the lung tissue and plasma). Since free radicals may further promote the release of inflammatory cytokines (37), the present study also revealed that a significant increase in the release of inflammatory cytokines IL-1 $\beta(\mathrm{P}<0.05$ in the lung and $\mathrm{P}<0.01$ in the plasma $)$ and TNF- $\alpha(\mathrm{P}<0.05$ in the lung and $\mathrm{P}<0.01$ in the plasma) in the lung during IIR was also inhibited by DEX. Among the oxidation products, MDA (38) and SOD (39) are always used to assess the degree of oxidative stress.

The affinity of DEX binding to $\alpha 2$-adrenergic receptors is 8 -fold greater compared with that of clonidine, and DEX has a half-life of $6 \mathrm{~min}$ and an elimination half-life of $2 \mathrm{~h}(29,40)$. Via $\alpha 2$-adrenergic receptors, DEX has demonstrated sedative, analgesic, anti-anxiety and diuresis effects $(40,41)$. In addition, the anti-apoptosis effect of DEX was inhibited by the $\alpha 2$-adrenoceptor antagonist ATI in liver ischemia-reperfusion injury and renal ischemia-reperfusion injury $(10,18)$. The present study further demonstrated that the antioxidant and anti-inflammatory action of DEX in lung injury during IIR was also acting on the $\alpha 2$-adrenoceptor.

Excessive ROS, produced during IIR, may overwhelm the antioxidant capacity and result in the oxidative stress of lung tissues $(42,43)$. Nrf 2 has been demonstrated to serve an important role in the protection against oxidant-associated lung, including ischemia reperfusion lung injury, ventilation-induced lung injury and sepsis-induced lung injury (44). Following activation, the conformation of the Nrf 2 complex changes, which inhibits the proteasomal degradation of $\mathrm{Nrf} 2$ and facilitates Nrf2 translocation into the nucleus to bind with antioxidant response element sequences in the promoter regions (43-46). Yan et al (47) reported that DEX alleviates LPS-induced lung injury via activating Nrf2/Keap1 signaling and inhibiting the inflammatory response and oxidative stress in rats. However, the molecular mechanisms underlying ALI/ARDS induced by IIR or LPS are different. IIR occurs due to the transient obliteration of the SMA and reperfusion of the ischemic bowel (48). As a common complication of IIR, lung injury is caused by a systemic inflammatory response due to the proinflammatory cytokines and bacteria-derived endotoxins released from the damaged intestine (49-51). Since the intestinal flora is complex, lung injury induced by IIR may be further complicated by gram-negative bacterial infections $(49,52,53)$. Pathological damage is more serious with alveolar exudation, bleeding and invasion of immune cells, in addition to the release of abundant cytokines and enzymes (53). Lipopolysaccharides (LPS) are a core constituent of gram-negative bacterial cell walls. Hence, LPS-induced lung injury is always used to study gram-negative bacterial-associated lung injury (54). The protective mechanisms of DEX on lung injury induced by IIR or LPS may not exactly be the same, since the activation of the Nrf2/HO-1 pathway has been reported to decrease oxidation products and improve intestinal mucosal injury in an IIR model (55). HO-1 is also a stress-responsive enzyme that produces antioxidants and anti-inflammatory agents (56). Therefore, the present study detected the effect of DEX on the Nrf2/HO-1 signaling pathway and revealed that pretreatment with DEX may activate the Nrf2/HO-1 signaling pathway in the pulmonary tissue of IIR rats. Through this method, DEX may decrease the oxidation products, inflammatory cytokines and pathological changes induced by IIR.

In conclusion, pretreatment with DEX exhibited potent antioxidant and anti-inflammatory properties in lung injury induced by IIR. The Nrf2/HO-1 signaling pathway may serve a function in the protective effect of DEX.

\section{Acknowledgements}

Not applicable.

\section{Funding}

The present study was supported by the Shanghai Jinshan Grants of National Health and Family Planning Commission, Shanghai, China (grant no. JSKJ-KTQN-2016-09).

\section{Availability of data and materials}

The datasets used and/or analyzed during the current study are available from the corresponding author on reasonable request.

\section{Authors' contributions}

BX designed the study. YC performed the experiments and analyzed the data. WB constructed the animal models, analyzed part of the data, wrote the manuscript and created the figures.

\section{Ethics approval and consent to participate}

All experimental procedures of the present study were performed in compliance with the National Institutes of Health Guide for the Care and Use of Laboratory Animals.

\section{Patient consent for publication}

Not applicable.

\section{Competing interests}

The authors declare that they have no competing interests.

\section{References}

1. Chen LW, Egan L, Li ZW, Greten FR, Kagnoff MF and Karin M: The two faces of IKK and NF-kappaB inhibition: Prevention of systemic inflammation but increased local injury following intestinal ischemia-reperfusion. Nat Med 9: 575-581, 2003.

2. Mallick IH, Yang W, Winslet MC and Seifalian AM: Ischemia-reperfusion injury of the intestine and protective strategies against injury. Dig Dis Sci 49: 1359-1377, 2004.

3. Li Y, Wen S, Yao X, Liu W, Shen J, Deng W, Tang J, LiC and Liu K: MicroRNA-378 protects against intestinal ischemia/reperfusion injury via a mechanism involving the inhibition of intestinal mucosal cell apoptosis. Cell Death Dis 8: e3127, 2017.

4. Tadros T, Traber DL, Heggers JP and Herndon DN: Effects of interleukin-1alpha administration on intestinal ischemia and reperfusion injury, mucosal permeability, and bacterial translocation in burn and sepsis. Ann Surg 237: 101-109, 2003.

5. Higuchi S, Wu R, Zhou M, Marini CP, Ravikumar TS and Wang P: Gut hyperpermiability after ischemia and reperfusion: Attenuation with adrenomedullin and its binding protein treatment. Int J Clin Exp Pathol 1: 409-418, 2008. 
6. Isik A, Peker K, Gursul C, Sayar I, Firat D, Yilmaz I and Demiryilmaz I: The effect of ozone and naringin on intestinal ischemia/reperfusion injury in an experimental model. Int J Surg 21: 38-44, 2015.

7. Chiang $\mathrm{CH}$, Pai $\mathrm{HI}$ and Liu SL: Ventilator-induced lung injury (VILI) promotes ischemia/reperfusion lung injury (I/R) and NF-kappaB antibody attenuates both injuries. Resuscitation 79: 147-154, 2008

8. Rahman I, Marwick J and Kirkham P: Redox modulation of chromatin remodeling: Impact on histone acetylation and deacetylation, NF-kappaB and pro-inflammatory gene expression. Biochem Pharmacol 68: 1255-1267, 2004.

9. Li A, Yuen VM, Goulay-Dufay S and Kwok PC: Pharmacokinetics and pharmacodynamics of dexmedetomidine. Drug Dev Ind Pharm 42: 1917-1927, 2016.

10. Sha J, Zhang H, Zhao Y, Feng X, Hu X, Wang C, Song M and Fan H: Dexmedetomidine attenuates lipopolysaccharide-induced liver oxidative stress and cell apoptosis in rats by increasing GSK-3 $\beta /$ MKP-1/Nrf2 pathway activity via the a2 adrenergic receptor. Toxicol Appl Pharmacol 364: 144-152, 2019.

11. Han J, Wang $M$, Jing $X$, Shi $H$, Ren $M$ and Lou $H$ : (-)-Epigallocatechin gallate protects against cerebral ischemia-induced oxidative stress via Nrf2/ARE signaling. Neurochem Res 39: 1292-1299, 2014.

12. Li L, Dong H, Song E, Xu X, Liu L and Song Y: Nrf2/ARE pathway activation, HO-1 and NQO1 induction by polychlorinated biphenyl quinone is associated with reactive oxygen species and PI3K/AKT signaling. Chem Biol Interact 209: 56-67, 2014.

13. Sies H, Berndt C and Jones DP: Oxidative atress. Annu Rev Biochem 86: 715-748, 2017.

14. Athale J, Ulrich A, MacGarvey NC, Bartz RR, Welty-Wolf KE, Suliman HB and Piantadosi CA: Nrf2 promotes alveolar mitochondrial biogenesis and resolution of lung injury in Staphylococcus aureus pneumonia in mice. Free Radic Biol Med 53: 1584-1294, 2012.

15. National Research Council (US) Committee for the Update of the Guide for the Care and Use of Laboratory Animals. Guide for the Care and Use of Laboratory Animals. 8th edition. Washington (DC), National Academies Press (US), 2011.

16. Zhang XY, Liu ZM, Wen SH, Li YS, Li Y, Yao X, Huang WQ and Liu KX: Dexmedetomidine administration before, but not after, ischemia attenuates intestinal injury induced by intestinal ischemia-reperfusion in rats. Anesthesiology 116: 1035-1046, 2012.

17. Stefanutti G, Pierro A, Parkinson EJ, Smith VV and Eaton S: Moderate hypothermia as a rescue therapy against intestinal ischemia and reperfusion injury in the rat. Crit Care Med 36: 1564-1572, 2018.

18. Li J, Chen Q, He X, Alam A, Ning J, Yi B, Lu K and Gu J Dexmedetomidine attenuates lung apoptosis induced by renal ischemia-reperfusion injury through a2AR/PI3K/Akt pathway. J Transl Med 16: 78, 2018.

19. Fu C, Dai X, Yang Y, Lin M, Cai Y and Cai S: Dexmedetomidine attenuates lipopolysaccharide-induced acute lung injury by inhibiting oxidative stress, mitochondrial dysfunction and apoptosis in rats. Mol Med Rep 15: 131-138, 2017.

20. Xue BB, Chen BH, Tang YN, Weng CW and Lin LN: Dexmedetomidine protects against lung injury induced by limb ischemia-reperfusion via the TLR4/MyD88/NF- $\kappa$ B pathway. Kaohsiung J Med Sci 35: 672-678, 2019.

21. Zhang $\mathrm{W}$ and Zhang J: Dexmedetomidine preconditioning protects against lung injury induced by ischemia-reperfusion through inhibition of autophagy. Exp Ther Med 14: 973-980, 2017.

22. Liang S, Wang Y and Liu Y: Dexmedetomidine alleviates lung ischemia-reperfusion injury in rats by activating PI3K/Akt pathway. Eur Rev Med Pharmacol Sci 23: 370-377, 2019.

23. Livak KJ and Schmittgen TD: Analysis of relative gene expression data using real-time quantitative PCR and the 2(-Delta Delta C(T)) method. Methods 25: 402-408, 2001.

24. Dong WW, Liu YJ, Lv Z, Mao YF, Wang YW, Zhu XY and Jiang L: Lung endothelial barrier protection by resveratrol involves inhibition of HMGB1 release and HMGB1-induced mitochondrial oxidative damage via an Nrf2-dependent mechanism. Free Radic Biol Med 88: 404-416, 2015.

25. Pryor WA and Stanley JP: Letter: A suggested mechanism for the production of malonaldehyde during the autoxidation of polyunsaturated fatty acids. Nonenzymatic production of prostaglandin endoperoxides during autoxidation. J Org Chem 40: 3615-3617, 1975.
26. Hayyan M, Hashim MA and AlNashef IM: Superoxide Ion: Generation and chemical implications. Chem Rev 116: 3029-3085, 2016

27. Eltzschig HK and Eckle T: Ischemia and reperfusion-from mechanism to translation. Nat Med 17: 1391-1401, 2011.

28. Toth B, Alexander M, Daniel T, Chaudry IH, Hubbard WJ and Schwacha MG: The role of gammadelta $\mathrm{T}$ cells in the regulation of neutrophil-mediated tissue damage after thermal injury. J Leukoc Biol 76: 545-552, 2004.

29. Coursin DB, Coursin DB and Maccioli GA: Dexmedetomidine. Curr Opin Crit Care 7: 221-226, 2001.

30. Chen Z, Ding T and Ma CG: Dexmedetomidine (DEX) protects against hepatic ischemia/reperfusion (I/R) injury by suppressing inflammation and oxidative stress in NLRC5 deficient mice. Biochem Biophys Res Commun 493: 1143-1150, 2017.

31. Si Y, Bao H, Han L, Chen L, Zeng L, Jing L, Xing Y and Geng Y: Dexmedetomidine attenuation of renal ischaemia-reperfusion injury requires sirtuin 3 activation. Br J Anaesth 121: 1260-1271, 2018.

32. Fang B, Li XQ, Bi B, Tan WF, Liu G, Zhang Y and Ma H: Dexmedetomidine attenuates blood-spinal cord barrier disruption induced by spinal cord ischemia reperfusion injury in rats. Cell Physiol Biochem 36: 373-383, 2015.

33. Yuan F, Fu H, Sun K, Wu S and Dong T: Effect of dexmedetomidine on cerebral ischemia-reperfusion rats by activating mitochondrial ATP-sensitive potassium channel. Metab Brain Dis 32: 539-546, 2017.

34. Cheng X, Hu J, Wang Y, Ye H, Li X, Gao Q and Li Z: Effects of dexmedetomidine postconditioning on myocardial Ischemia/Reperfusion injury in diabetic rats: Role of the PI3K/Akt-dependent signaling pathway. J Diabetes Res 2018: 3071959, 2018.

35. Cui J,Zhao H, Wang C, Sun JJ,Lu K and Ma D: Dexmedetomidine attenuates oxidative stress induced lung alveolar epithelial cell apoptosis in vitro. Oxid Med Cell Longev 2015: 358396, 2015.

36. Gao S, Wang Y, Zhao J and Su A: Effects of dexmedetomidine pretreatment on heme oxygenase-1 expression and oxidative stress during one-lung ventilation. Int J Clin Exp Pathol 8: 3144-3149, 2015.

37. Ward PA: Oxidative stress: Acute and progressive lung injury. Ann N Y Acad Sci 1203: 53-59, 2010.

38. Lei J, Wei Y, Song P, Li Y, Zhang T, Feng Q and Xu G: Cordycepin inhibits LPS-induced acute lung injury by inhibiting inflammation and oxidative stress. Eur J Pharmacol 818: 110-114, 2018.

39. McCord JM and Edeas MA: SOD, oxidative stress and human pathologies: A brief history and a future vision. Biomed Pharmacother 59: 139-142, 2015.

40. Paris A and Tonner PH: Dexmedetomidine in anaesthesia. Curr Opin Anaesthesiol 18: 412-418, 2005.

41. Carollo DS, Nossaman BD and Ramadhyani U: Dexmedetomidine: A review of clinical applications. Curr Opin Anaesthesiol 21: 457-461, 2018

42. Poljsak B, Suput D and Milisav I: Achieving the balance between ROS and antioxidants: When to use the synthetic antioxidants. Oxid Med Cell Longev 2013: 956792, 2013.

43. Zhao W, Gan X, Su G, Wanling G, Li S, Hei Z, Yang C and Wang H: The interaction between oxidative stress and mast cell activation plays a role in acute lung injuries induced by intestinal ischemia-reperfusion. J Surg Res 187: 542-552, 2014.

44. Hybertson BM and Gao B: Role of the Nrf2 signaling system in health and disease. Clin Genet 86: 447-452, 2014.

45. de Roos B and Duthie GG: Role of dietary pro-oxidants in the maintenance of health and resilience to oxidative stress. Mol Nutr Food Res 59: 1229-1248, 2015.

46. Tkachev VO, Menshchikova EB and Zenkov NK: Mechanism of the Nrf2/Keap1/ARE signaling system. Biochemistry (Mosc) 76: 407-422, 2011.

47. Yan X, Cheng X, Zhou L, He X, Zheng W and Chen H: Dexmedetomidine alleviates lipopolysaccharide-induced lung injury in Wistar rats. Oncotarget 8: 44410-44417, 2017.

48. Nadatani Y, Watanabe T, Shimada S, Otani K, Tanigawa T and Fujiwara Y: Microbiome and intestinal ischemia/reperfusion injury. J Clin Biochem Nutr 63: 26-32, 2018.

49. Bellingan GJ: The pulmonary physician in critical care* 6 : The pathogenesis of ALI/ARDS. Thorax 57: 540-546, 2002.

50. Souza DG, Vieira AT, Soares AC, Pinho V, Nicoli JR, Vieira LQ and Teixeira MM: The essential role of the intestinal microbiota in facilitating acute inflammatory responses. J Immunol 173: 4137-4146, 2004. 
51. Tamion F, Richard V, Lyoumi S, Daveau M, Bonmarchand G, Leroy J, Thuillez C and Lebreton JP: Gut ischemia and mesenteric synthesis of inflammatory cytokines after hemorrhagic or endotoxic shock. Am J Physiol 273: G314-G321, 1997.

52. Ware LB and Matthay MA: The acute respiratory distress syndrome. N Engl J Med 342: 1334-1349, 2000.

53. Cui T, Miksa M, Wu R, Komura H, Zhou M, Dong W, Wang Z, Higuchi S, Chaung W, Blau SA, et al: Milk fat globule epidermal growth factor 8 attenuates acute lung injury in mice after intestinal ischemia and reperfusion. Am J Respir Crit Care Med 181: 238-246, 2010

54. Chen H, Bai C and Wang X: The value of the lipopolysaccharide-induced acute lung injury model in respiratory medicine. Expert Rev Respir Med 4: 773-783, 2010.
55. Zu G, Zhou T, Che N and Zhang X: Salvianolic acid A protects against oxidative stress and apoptosis induced by intestinal ischemia-reperfusion injury through activation of $\mathrm{Nrf} 2 / \mathrm{HO}-1$ pathways. J Biol Chem 49: 2320-2332, 2018.

56. Fan J, Xu G, Jiang T and Qin Y: Pharmacologic induction of heme oxygenase- 1 plays a protective role in diabetic retinopathy in rats. Invest Ophthalmol Vis Sci 53: 6541-6556, 2012.

This work is licensed under a Creative Commons Attribution-NonCommercial-NoDerivatives 4.0 International (CC BY-NC-ND 4.0) License. 